\title{
The Australasian Diabetes Data Network: first national audit of children and adolescents with type 1 diabetes
}

\author{
Helen Phelan ${ }^{1,2}$, Helen Clapin ${ }^{3,4}$, Loren Bruns ${ }^{5}$, Fergus J Cameron ${ }^{6}$, Andrew M Cotterill ${ }^{7,8}$, Jennifer J Couper ${ }^{9}$, \\ Elizabeth A Davis ${ }^{10}$, Kim C Donaghue ${ }^{17}$, Craig A Jefferies ${ }^{12}$, Bruce R King ${ }^{1}$, Richard O Sinnott ${ }^{5}$, Elaine B Tham ${ }^{9}$, \\ Jerry K Wales ${ }^{7,8}$, Timothy W Jones ${ }^{10}$, Maria E Craig ${ }^{2,11}$
}

The known International diabetes registries report that many young people with type 1 diabetes do not meet recommended targets for glycaemic control. Relevant Australian data have been lacking.

The new $73 \%$ of Australian children and adolescents with type 1 diabetes do not meet the recommended target for glycaemic control. Uptake of intensive insulin therapy varies between diabetes centres. Rates of overweight and obesity were higher than for this age group in the general population.

The implications Strategies for improving glycaemic control in young people with diabetes are urgently needed to prevent the acute and chronic complications of this disorder.

\footnotetext{
L
}

arge population-based diabetes registers in several countries have collated data on glycaemic control, management and clinical outcomes for young people with diabetes, facilitating the international benchmarking of paediatric diabetes centres. ${ }^{1}$ Analysis of these databases has indicated that glycaemic control in many young people with type 1 diabetes is suboptimal; $54-84 \%$ do not achieve the internationally established target haemoglobin $\mathrm{A}_{1 \mathrm{c}}\left(\mathrm{HbA}_{1 \mathrm{c}}\right)$ level for young people (below $58 \mathrm{mmol} / \mathrm{mol}$ ). ${ }^{2,3}$ This statistic has prompted discussion of the evidence-based management of childhood diabetes and the most effective application of emerging therapies. Several registers have reported improved glycaemic control over time, ${ }^{4,5}$ and it has been proposed that benchmarking activity, consisting of actively identifying problems and adopting systematic improvement methods (including reporting of results by centre), has contributed to improving patient outcomes. $^{5}$

In Australia, state-based diabetes incidence registers have operated for more than 20 years; the National Diabetes Register (NDR), which sources data from these registers, was established in $1999 .{ }^{6}$ However, the NDR reports only the overall incidence and prevalence of insulin-treated diabetes in Australia. While a number of paediatric diabetes centres with established clinical databases have reported clinical outcomes for younger patients over recent decades, ${ }^{7-10}$ there has been no national surveillance of glycaemic control or the management of diabetes in young people. More recently, a national audit of paediatric diabetes centres described variations in staffing and resources, and reported that clinician-to-patient ratios were below recommended levels, particularly in allied health care and psychological services. $^{11}$

\section{Abstract}

Objectives: To assess glycaemic control, anthropometry and insulin regimens in a national sample of Australian children and adolescents with type 1 diabetes.

Design: Cross-sectional analysis of de-identified, prospectively collected data from the Australasian Diabetes Data Network (ADDN) registry.

Setting: Five paediatric diabetes centres in New South Wales, Queensland, South Australia, Victoria and Western Australia.

Participants: Children and adolescents (aged 18 years or under) with type 1 diabetes of at least 12 months' duration for whom data were added to the ADDN registry during 2015.

Main outcome measures: Glycaemic control was assessed by measuring haemoglobin $A_{l c}\left(H_{b} A_{l c}\right)$ levels. Body mass index standard deviation scores (BMI-SDS) were calculated according to the CDC-2000 reference; overweight and obesity were defined by International Obesity Task Force guidelines. Insulin regimens were classified as twice-daily injections (BD), multiple daily injections (MDI; at least three injection times per day), or continuous subcutaneous insulin infusion (CSII).

Results: The mean age of the 3279 participants was 12.8 years (SD, 3.7), mean diabetes duration was 5.7 years (SD, 3.7), and mean $\mathrm{HbA}_{l c}$ level $67 \mathrm{mmol} / \mathrm{mol}(\mathrm{SD}, 15)$; only $27 \%$ achieved the national $\mathrm{HbA}_{1 c}$ target of less than $58 \mathrm{mmol} / \mathrm{mol}$. The mean $\mathrm{HbA}_{\mathrm{lc}}$ level was lower in children under $6(63 \mathrm{mmol} / \mathrm{mol})$ than in adolescents (14-18 years; $69 \mathrm{mmol} / \mathrm{mol}$ ). Mean BMI-SDS for all participants was 0.6 (SD, 0.9); 33\% of the participants were overweight or obese. $44 \%$ were treated with CSII, 38\% with MDI, $18 \%$ with BD.

Conclusions: Most Australian children and adolescents with type 1 diabetes are not meeting the recognised $\mathrm{HbA}_{1 c}$ target. The prevalence of overweight and obesity is high. There is an urgent need to identify barriers to achieving optimal glycaemic control in this population.

The Australasian Diabetes Data Network (ADDN) is a prospective longitudinal diabetes register that provides the first opportunity for the long term monitoring of diabetes outcomes of a national sample of Australian patients. The ADDN is an initiative of the Australasian Paediatric Endocrine Group (APEG), the Australian Diabetes Society (ADS), and the Juvenile Diabetes Research Foundation Australia Clinical Research Network. The development of the ADDN has been described in detail elsewhere. ${ }^{12}$ In this article, we report on glycaemic control, anthropometry, and insulin regimens in a cross-section of Australian children and adolescents with type 1 diabetes.

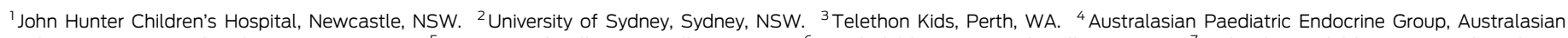

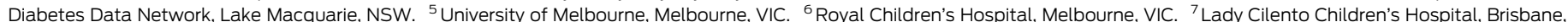

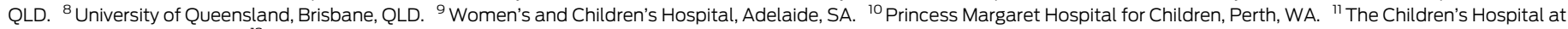
Westmead, Sydney, NSW. ${ }^{12}$ The Starship Children's Hospital, Auckland, New Zealand. @ m.craig@unsw.edu.au•doi: 10.5694/mja16.00737. See Editorial, p. 118 


\section{Methods}

The ADDN model involves the transfer of de-identified, prospectively collected patient data from the clinical databases or electronic medical record systems of participating ADDN centres to a web-based staging server hosted by the University of Melbourne. Participating centres collect data using a common data dictionary. Data are transferred every 6 months to the ADDN registry from the five largest paediatric diabetes centres in Australia, located in New South Wales, Queensland, South Australia, Victoria and Western Australia.

We analysed data extracted from the ADDN registry for 1 January 2015 - 31 December 2015 for patients who had been diagnosed with type 1 diabetes at least 12 months before their visit to the paediatric diabetes centre, and who were 18 years old or younger at the time of the visit.

Glycaemic control was assessed by measuring $\mathrm{HbA}_{1 \mathrm{c}}$ levels, using either point-of-care or laboratory methods that complied with national accreditation programs for laboratory testing. Body mass index standard deviation scores (BMI-SDS; measures of relative weight adjusted for child age and sex) were calculated from height and weight, using the Centers for Disease Control and Prevention 2000 reference scale for children aged 2-18 years (CDC-2000). ${ }^{13}$ Children were classified as either normal/underweight, overweight, or obese according to the International Obesity Task Force guidelines. ${ }^{14}$ Insulin regimens were classified as twice-daily injections (BD), multiple daily injections (MDI; ie, at least three injection times per day), or continuous subcutaneous insulin infusion (CSII). Mean $\mathrm{HbA}_{1 \mathrm{c}}$ levels and BMI-SDS were estimated for each participant over the 12-month study period, with the most recent recorded insulin regimen used for analysis. The descriptive statistics reported are means with standard deviations (SDs) for normally distributed variables and medians with interquartile ranges (IQRs) for skewed data. Statistical analyses were performed in Stata IC 14.0 (StataCorp).

\section{Ethics approval}

Ethics approval was granted by the Hunter New England Human Research Ethics Committee (HREC) (for all New South Wales sites: reference, 08/11/19/5.04), the Children's Health Services Queensland HREC (for all Queensland sites: reference, HREC/ 09/QRCH/68; amendment: HREC/09/QRCH/68/AM02), the Women's and Children's Health Network HREC (for all South Australian sites: reference, REC1048/2/16), the Royal Children's Hospital HREC (for all Victorian sites: reference, DAF DA0322014-01), and the Princess Margaret Hospital for Children HREC (for all Western Australian sites: reference, 2013051EP). Informed consent was obtained from parents and from adolescents over 14 years old, and, when required by the HREC, assent was obtained from children aged 10-14 years.

\section{Results}

The clinical characteristics of the 3279 children and adolescents meeting the inclusion criteria for whom data were registered in the ADDN registry during 2015 are shown in Box 1, stratified by centre. $52 \%$ were boys. Clinical characteristics stratified by age group and insulin regimen are presented in Box 2.

\section{Glycaemic control}

The mean number of $\mathrm{HbA}_{1 \mathrm{c}}$ measurements per patient was 3.0 (SD, $1.1) ; 99 \%$ of the patients had at least one recorded $\mathrm{HbA}_{1 \mathrm{c}}$ measurement during 2015. The mean $\mathrm{HbA}_{1 \mathrm{c}}$ level was $67 \mathrm{mmol} / \mathrm{mol}$ (SD, $15 \mathrm{~mol} / \mathrm{mol}$; Box 1). Mean $\mathrm{HbA}_{1 \mathrm{c}}$ level increased with age,

1 Clinical characteristics of Australian children and adolescents with type 1 diabetes, as registered in the Australasian Diabetes Data Network (ADDN) registry during 2015, by ADDN centre

Australasian Diabetes Data Network centre

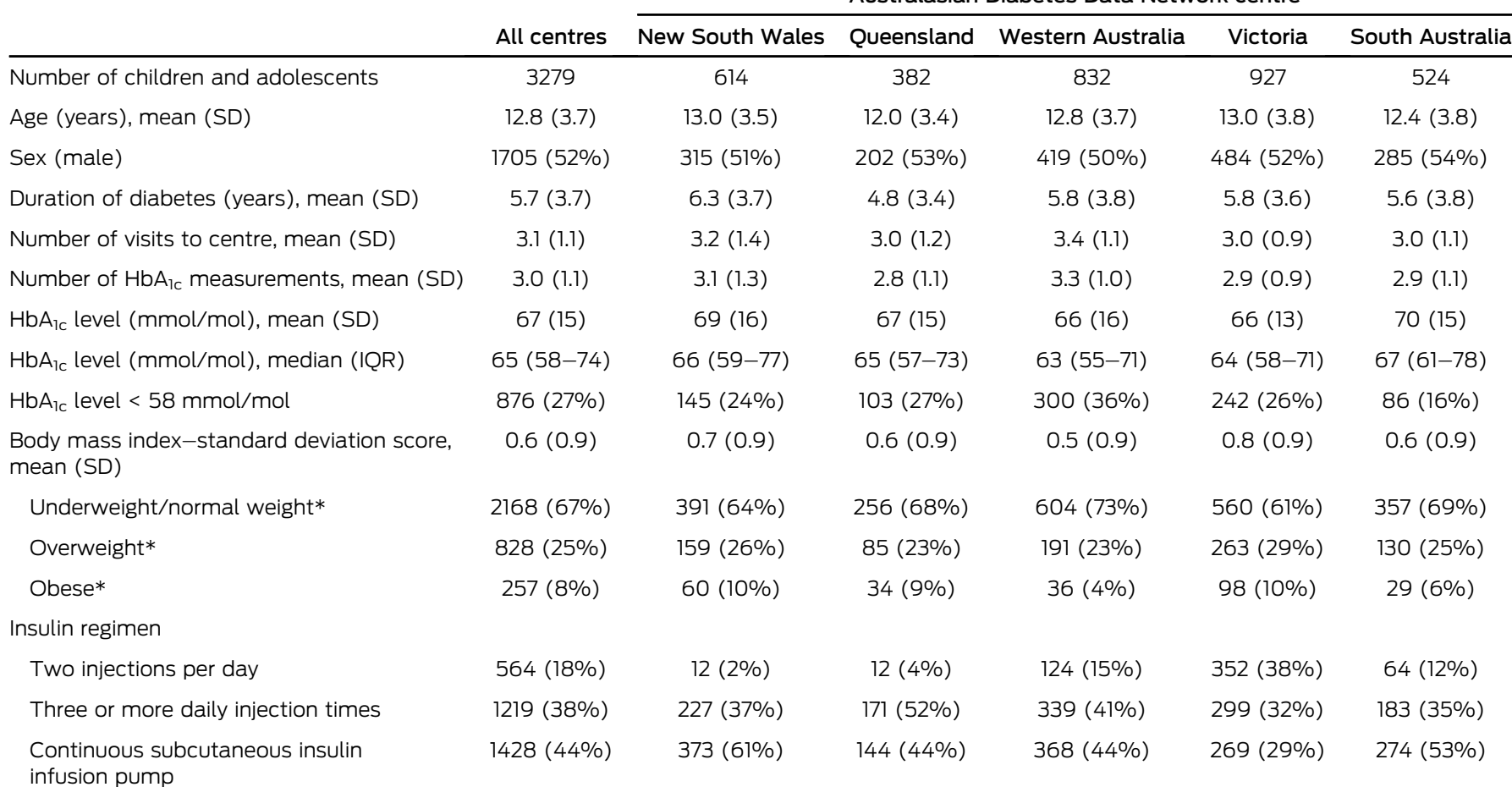


2 Clinical characteristics of Australian children and adolescents with type 1 diabetes, as registered in the Australasian Diabetes Data Network registry during 2015, by age group and insulin regimen

\begin{tabular}{|c|c|c|c|c|}
\hline & \multicolumn{4}{|c|}{ Average age over 12 months (2015) } \\
\hline & $\leq 6$ years & $<6-10$ years & $>10-14$ years & $>14-18$ years \\
\hline $\begin{array}{l}\text { Number of children and adolescents (proportion } \\
\text { of all participants) }\end{array}$ & $185(6 \%)$ & $575(18 \%)$ & $1094(33 \%)$ & $1425(44 \%)$ \\
\hline Sex (male) & 109 (59\%) & $308(54 \%)$ & $540(49 \%)$ & $748(52 \%)$ \\
\hline Duration of diabetes (years), mean (SD) & $2.2(1.0)$ & $3.7(2.0)$ & $5.3(3.1)$ & $7.4(4.0)$ \\
\hline \multicolumn{5}{|l|}{ Insulin regimen } \\
\hline Two injections per day & $61(34 \%)$ & $193(34 \%)$ & $162(15 \%)$ & $148(10 \%)$ \\
\hline Three or more daily injection times & $41(23 \%)$ & $124(22 \%)$ & $396(37 \%)$ & $658(46 \%)$ \\
\hline Continuous subcutaneous insulin infusion pump & $79(43 \%)$ & $243(44 \%)$ & $510(48 \%)$ & $596(43 \%)$ \\
\hline \multicolumn{5}{|l|}{$\mathrm{HbA}_{\mathrm{lc}}$ level $(\mathrm{mmol} / \mathrm{mol})$, mean (SD) } \\
\hline All regimens & $63(11)$ & $62(10)$ & $68(14)$ & $69(17)$ \\
\hline Two injections per day & $65(12)$ & $64(11)$ & $70(15)$ & $77(19)$ \\
\hline Three or more daily injection times & $63(10)$ & $63(10)$ & $69(15)$ & $70(17)$ \\
\hline Continuous subcutaneous insulin infusion pump & $62(9)$ & $60(8)$ & $66(11)$ & $67(15)$ \\
\hline $\mathrm{HbA}_{1 \mathrm{c}}<58 \mathrm{mmol} / \mathrm{mol}$ & $62(34 \%)$ & $202(35 \%)$ & $260(24 \%)$ & $352(25 \%)$ \\
\hline Body mass index-standard deviation score, mean (SD) & $1.0(0.9)$ & $0.6(0.7)$ & $0.5(0.9)$ & $0.7(0.9)$ \\
\hline Underweight/normal weight* & $112(61 \%)$ & $436(76 \%)$ & $753(69 \%)$ & $867(61 \%)$ \\
\hline Overweight* & $56(31 \%)$ & $107(19 \%)$ & $261(24 \%)$ & $404(29 \%)$ \\
\hline Obese* & $15(8 \%)$ & $32(6 \%)$ & $70(7 \%)$ & $140(10 \%)$ \\
\hline
\end{tabular}

from $63 \mathrm{mmol} / \mathrm{mol}(\mathrm{SD}, 11 \mathrm{~mol} / \mathrm{mol})$ in children aged 6 years or under to $69 \mathrm{mmol} / \mathrm{mol}$ (SD, $17 \mathrm{~mol} / \mathrm{mol}$ ) in adolescents $14-18$ years old (Box 2). Overall, $3 \%$ of patients had $\mathrm{HbA}_{1 \mathrm{c}}$ levels greater than $108 \mathrm{mmol} / \mathrm{mol}$; only $27 \%$ met the APEG/ADS national guidelines target level of less than $58 \mathrm{mmol} / \mathrm{mol}^{3}$ and the proportion of children and adolescents meeting this target declined with age, from $34 \%$ of those aged 6 years or less to $25 \%$ of those aged $14-18$ years (Box 3 ). When stratified by insulin regimen, there was little difference in mean $\mathrm{HbA}_{1 \mathrm{c}}$ level within age groups, but adolescents (14-18 years old) treated with BD insulin had the highest mean $\mathrm{HbA}_{1 \mathrm{c}}$ levels $(77 \mathrm{mmol} / \mathrm{mol}$; $\mathrm{SD}, 19 \mathrm{mmol} / \mathrm{mol}$; Box 2).

\section{Anthropometry}

Anthropometric measurements were available for $99 \%$ of participants. The mean BMI-SDS was 0.6 (SD, 0.9). Children aged 6 or less had higher BMI-SDS scores than older children and adolescents. The prevalence of being overweight was $25 \%$ and of obesity $8 \%$, with the highest proportions in the youngest and the oldest children (Box 1, Box 2).

\section{Insulin regimen}

The insulin regimen was recorded for $98 \%$ of participants: CSII was used by $44 \%$, MDI by $38 \%$, and BD by $18 \%$. The pattern of insulin regimen use varied between ADDN centres (Box 1) and age groups (Box 2); BD regimens were more frequent in the youngest age groups, with more than one-third of children under 10 using BD insulin therapy.

\section{Discussion}

In this first nationwide snapshot of Australian children and adolescents with type 1 diabetes, fewer than one-third had attained the national and international recommended $\mathrm{HbA}_{1 \mathrm{c}}$ target level of less than $58 \mathrm{mmol} / \mathrm{mol}^{2,3}$ It has been established that the risk of microvascular and macrovascular complications is increased for children and adolescents who do not reach this target; evidence is also emerging that poor glycaemic control in childhood persists into adulthood, increasing the lifetime risk of complications. ${ }^{15}$

3 Haemoglobin $A_{1 c}\left(\mathrm{HbA}_{1 c}\right)$ levels of 3279 Australian children and adolescents with type 1 diabetes, as registered in the Australasian Diabetes Data Network registry during 2015, by age group

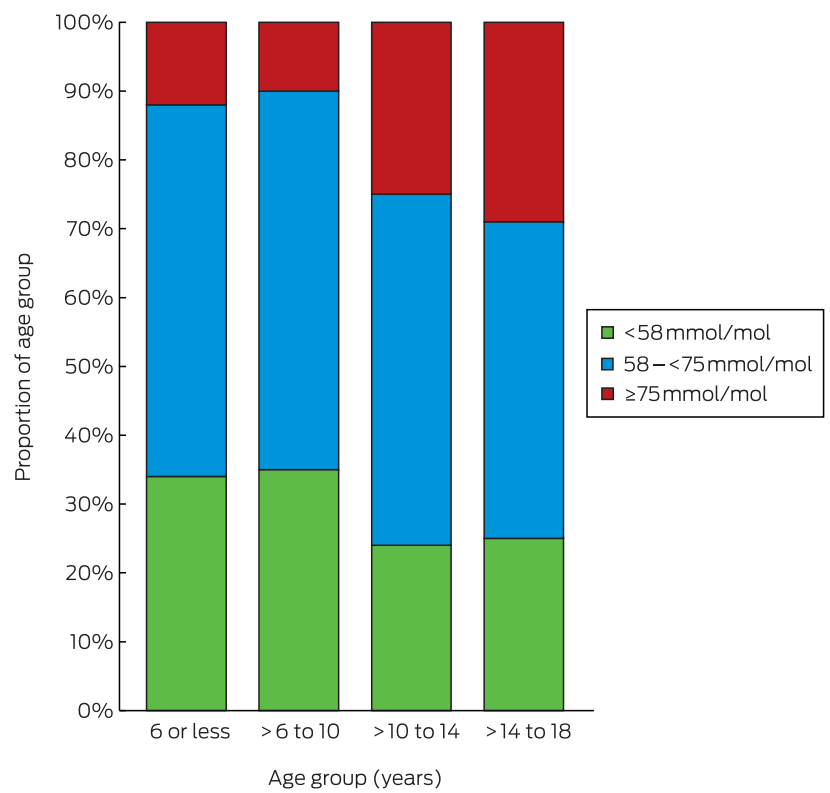


One-third of children and adolescents in our snapshot were overweight or obese, conditions also associated with a greater risk of complications and other comorbidities. ${ }^{16}$

The proportion of Australian children and adolescents achieving appropriate glycaemic control is comparable with that reported by a number of overseas registries, ${ }^{1}$ but lower than that in Sweden and Germany, where $41 \%$ and $49 \%$ respectively achieved the target. ${ }^{4,5}$ It is concerning that the national median $\mathrm{HbA}_{1 \mathrm{c}}$ level in 2015 was similar to that reported in NSW in $1999(8.2 \%=66 \mathrm{mmol} / \mathrm{mol})^{17}$ and that the proportion of young people reaching the recommended glycaemic control target in 2015 was similar to that in Brisbane in 1998 (33\%). ${ }^{7}$ Further, our participants were all treated in specialist tertiary referral diabetes centres; as the ADDN database expands to include children from less specialised centres, the characteristics of the participant group may change. Our results indicate a need to substantially improve outcomes, a common theme worldwide.

Managing diabetes in adolescents is particularly challenging for clinicians. Parental involvement in the self-management of diabetes by adolescents often declines at the same time as the changes associated with the metabolic effects of puberty and growth commence. Only one-quarter of the 1425 adolescents (14-18 years) in our study met the recommended target for glycaemic control. We did not assess people over 18, but evidence is emerging that the deterioration of glycaemic control during adolescence continues into early adulthood, and does not improve to recommended levels before age $30 ;{ }^{15}$ limited Australian data also indicate that targets for glycaemic control are not even closely approached by young adults. $^{18}$

The ADDN centres included in this report are all publicly funded hospitals in metropolitan areas with comparable patient numbers, so we were not surprised to find similar levels of glycaemic control. We had incomplete data about the ethnic background and socioeconomic status of the participants, factors known to influence glycaemic control in other populations; children from minority groups or socio-economically disadvantaged backgrounds in the United Kingdom, for example, were reported to have higher $\mathrm{HbA}_{1 \mathrm{c}}$ levels. ${ }^{19}$ Ideally, the effect of these and other modifiable factors on levels of glycaemic control should be explored using longitudinal data adjusted for confounders. This is one of the major goals of the ADDN, and our report provides important baseline data.

The mean of 3.1 visits by patients to diabetes centres each year is lower than the 3.7 reported by a national audit in $2010 .{ }^{11} \mathrm{HbA}_{1 \mathrm{c}}$ is assessed routinely during such visits, and the mean annual number of $\mathrm{HbA}_{1 \mathrm{c}}$ measurements was 3.0 per patient in our sample. In a recent report based on data for more than 79000 patients with diabetes in the $\mathrm{UK}$, less frequent $\mathrm{HbA}_{1 \mathrm{c}}$ assessment was associated with poorer glycaemic control; the optimal frequency was four times per year. ${ }^{20}$ The ADDN centres included in this report are tertiary referral centres with multidisciplinary diabetes teams, but we did not examine the types of health professional seen by the patient, nor the overall staff structure of the diabetes teams. Nevertheless, limited access to the full range of allied health professionals recommended for the intensive management of diabetes was reported in 2010, ${ }^{11}$ and the relationship between staffing levels and glycaemic control should be investigated in future analyses.

To reduce the risk of vascular complications, intensive insulin therapy, including MDI or CSII therapy, is recommended for children, adolescents and adults with type 1 diabetes. ${ }^{3}$ Clinicians must balance this recommendation against individual patient characteristics and the specific clinical situation. In our study, more than one-third of children under 10 years of age were treated with
BD insulin therapy. This may reflect the challenges of managing diabetes in the school setting and the capacity of schools to provide adequate support for intensive insulin therapy. ${ }^{21}$

The overall uptake of CSII in this sample was $44 \%$; the rate varied little between age groups, but differed between ADDN centres. The consistency of CSII uptake across age groups contrasts with a recent report from three registries including data for 54410 children and adolescents with type 1 diabetes recruited from clinics in Germany and Austria, the United States and the UK. ${ }^{22}$ In Germany and Austria, about $70 \%$ of children under 6 years of age with type 1 diabetes were treated with CSII, compared with $35-40 \%$ of older children. In the US, $30 \%$ of children under 6 used CSII, compared with $40-45 \%$ of older children, while in the UK $15-20 \%$ of children across all age groups used CSII. In a pooled cross-sectional analysis of data from the three registries, the mean $\mathrm{HbA}_{1 \mathrm{c}}$ level was $5.5 \mathrm{mmol} / \mathrm{mol}$ lower in children and adolescents treated with CSII than in those using insulin injections. Similarly, an Australian study of children and adolescents with type 1 diabetes found a mean reduction of $6.6 \mathrm{mmol} / \mathrm{mol} \mathrm{HbA}_{1 \mathrm{c}}$ associated with CSII. ${ }^{23}$

In our sample, there was little variation in mean $\mathrm{HbA}_{1 \mathrm{c}}$ levels between centres, despite the differing uptake of CSII. However, patient selection bias is possible when comparing outcomes according to their insulin regimens. For example, adolescents with high $\mathrm{HbA}_{1 \mathrm{c}}$ levels may be moved from more intensive treatment to the simpler BD therapy in an attempt to improve glycaemic control. The relationship between $\mathrm{HbA}_{1 \mathrm{c}}$ level and insulin therapy should be examined by multivariable analysis of longitudinal data, with adjustment for potential confounders. The rates of CSII use in different countries may reflect variations in funding models, clinical practice, and patient demand. In Australia, insulin pumps are available to patients with private health insurance, or through a means-tested pump access program administered by Juvenile Diabetes Research Foundation (JDRF) Australia. It would be valuable to further explore the factors that influence choice of therapeutic regimen for Australian children and adolescents with type 1 diabetes.

In our sample, $33 \%$ of children and adolescents with type 1 diabetes were overweight or obese, with little difference between ADDN centres. This is higher than the rate $(27 \%)$ for children and adolescents in the general population. ${ }^{24}$ Our finding is consistent with the reported rate for children and adolescents under 16 with type 1 diabetes in NSW. ${ }^{25}$ The youngest children had the highest mean BMI-SDS scores; the proportions who were overweight or obese were highest for the youngest and oldest children. This contrasts with a 2007 report from Victoria that the mean BMI-SDS was lowest $(0.64)$ in children with type 1 diabetes under 5 years of age. ${ }^{26}$ Healthy weight is an important goal for children and adolescents with type 1 diabetes, as being overweight has implications for long term health. Further, obesity, as a marker of insulin resistance, is associated with early neuropathy ${ }^{16}$ and retinopathy, as well as with higher $\mathrm{HbA}_{1 \mathrm{c}}$ levels and rates of severe hypoglycaemia. ${ }^{27}$ The challenges for maintaining healthy weight associated with type 1 diabetes include weight gain as the result of supra-physiological insulin doses, and overeating to avoid or treat hypoglycaemia.

Our survey of glycaemic control involved more than 3000 children and adolescents with type 1 diabetes from diverse geographic regions, but we do not know if our data are representative of all Australian children with type 1 diabetes, as the participants were seen in five large tertiary, city-based diabetes centres. Further, ascertainment of data differed between states: most children with type 1 diabetes in WA are managed at one centre, in contrast to 
other states, where diabetes care is less centralised. As the ADDN enters phase 2, when it will include regional and remote and adult diabetes centres, the representativeness of the available data will improve.

In conclusion, the ADDN project has shown that benchmarking glycaemic control, use of insulin therapies, and anthropometry across Australian paediatric diabetes centres is feasible. It is worrying that less than one-third of Australian children and adolescents with diabetes type 1 met the recommended target for glycaemic control, and that rates of being overweight or obese were higher than in the general Australian population of children and adolescents. As the ADDN registry grows, so will its ability to explore and understand the factors that influence clinical outcomes for Australian children and adolescents, supporting our aim of continually appraising and improving the diabetes services we provide.

Acknowledgements: This research was supported by the Australian Type 1 Diabetes Clinical Research Network, led by Juvenile Diabetes Research Foundation (JDRF) Australia, with additional funding by the Australian Research Council (through a Special Research Initiative) and the federal Department of Health and Ageing. Helen Phelan received a National Health and Medical Research Council (NHMRC) Public Health and Health Services Research Scholarship. We thank the staff of the JDRF Australian Type 1 Clinical Research Network, particularly Dorota Pawlak and Maryanne Ng, for ongoing support and guidance. We gratefully acknowledge the contribution and support of the Australasian Paediatric Endocrine Group (APEG) and Lyndell Wills, APEG Secretariat, and we also thank Albert Chan, Children's Hospital Westmead, Sydney, and Girard Good, Telethon Kids Institute, Perth, for developing the clinical database and preparing data exports to the ADDN.

Competing interests: No relevant disclosures.

Received 20 June 2016, accepted 12 Sept 2016.

(c) 2017 AMPCo Pty Ltd. Produced with Elsevier B.V. All rights reserved.
1 McKnight JA, Wild SH, Lamb MJ, et al. Glycaemic control of type 1 diabetes in clinical practice early in the 21st century: an international comparison. Diabet Med 2015; 32: 1036-1050.

2 Rewers MJ, Pillay K, de Beaufort C, et al; International Society for Pediatric and Adolescent Diabetes. ISPAD Clinical Practice Consensus Guidelines 2014. Assessment and monitoring of glycemic control in children and adolescents with diabetes. Pediatr Diabetes 2014; 15 Suppl 20: 102-114.

3 Craig ME, Twigg SM, Donaghue KC, et al; for the Australian Type 1 Diabetes Guidelines Expert Advisory Group. National evidence-based clinical care guidelines for type 1 diabetes in children, adolescents and adults. Canberra: Australian Government. Department of Health and Ageing, 2011. https://diabetessociety.com. au/documents/Typelguidelines14Nov2011.pdf (accessed Mar 2016).

4 Rosenbauer J, Dost A, Karges B, et al; DPV initiative and the German BMBF Competence Network Diabetes Mellitus. Improved metabolic control in children and adolescents with type 1 diabetes: a trend analysis using prospective multicenter data from Germany and Austria. Diabetes Care 2012; 35: 80-86.

5 Peterson A, Hanberger L, Akesson K, et al. Improved results in paediatric diabetes care using a quality registry in an improvement collaborative: a case study in Sweden. PLoS One 2014; 9: e97875.

6 Catanzariti L, Faulks K, Moon L, et al. Australia's national trends in the incidence of Type 1 diabetes in 0-14-year-olds, 2000-2006. Diabet Med 2009; 26: 596-601.

7 Thomsett M, Shield G, Batch J, et al. How well are we doing? Metabolic control in patients with diabetes. J Paediatr Child Health 1999; 35: 479-482.

8 Cameron FJ, Clarke C, Hesketh K, et al. Regional and urban Victorian diabetic youth: clinical and quality-of-life outcomes. J Paediatr Child Health 2002; 38: 593-596.

9 Cooper MN, O'Connell SM, Davis EA, et al. A populationbased study of risk factors for severe hypoglycaemia in a contemporary cohort of childhood-onset type 1 diabetes. Diabetologia 2013; 56: 2164-2170.

10 Downie E, Craig ME, Hing S, et al. Continued reduction in the prevalence of retinopathy in adolescents with type 1 diabetes: role of insulin therapy and glycemic control. Diabetes Care 2011; 34: 2368-2373.

11 Cameron FJ, Couper JJ, Craig ME, et al. Care for children and adolescents with diabetes in Australia and New Zealand: Have we achieved the defined goals? J Paediatr Child Health 2013; 49: E258-E262.

12 Clapin $\mathrm{H}$, Phelan $\mathrm{H}$, Bruns L, et al; on behalf of the Australasian Diabetes Data Network (ADDN) Study Group. Australasian Diabetes Data Network: building a collaborative resource. J Diabetes Sci Technol 2016; 10: 1015-1026.

13 Centers for Disease Control and Prevention, National Center for Health Statistics. CDC growth charts [website]. http://www.cdc.gov/growthcharts/cdc charts.htm (accessed Nov 2016).

14 Cole TJ, Belizzi MC, Flegal KM, et al. Establishing a standard definition for child overweight and obesity worldwide: international survey. BMJ 2000; 320: 1240-1243.

15 Miller KM, Foster NC, Beck RW, et al; for the TID Exchange Clinic Network. Current state of type 1 diabetes treatment in the US: updated data from the TID Exchange Clinic Registry. Diabetes Care 2015; 38: 971-978.

16 Stone ML, Craig ME, Chan AK, et al. Natural history and risk factors for microalbuminuira in adolescents with type 1 diabetes: a longitudinal study. Diabetes Care 2006; 29: 2072-2077.

17 Craig ME, Handelsman P, Donaghue KC, et al. Predictors of glycaemic control and hypoglycaemia in children and adolescents with type 1 diabetes from NSW and the ACT. Med J Aust 2002; 177: 235-238. https:// www.mja.com.au/journal/2002/177/5/predictorsglycaemic-control-and-hypoglycaemia-children-andadolescents-type-1

18 Perry L, Steinbeck KS, Dunbabin JS, et al. Lost in transition? Access to and uptake of adult health services and outcomes for young people with type 1 diabetes in regional New South Wales. Med J Aust 2010; 193 444-449. https://www.mja.com.au/journal/2010/193/8/ lost-transition-access-and-uptake-adult-healthservices-and-outcomes-young-people

19 Khanolkar AR, Amin R, Taylor-Robinson D, et al. Young people with type 1 diabetes of non-white ethnicity and lower socio-economic status have poorer glycaemic control in England and Wales. Diabet Med 2016; 33:1508-1515.

20 Driskell $\mathrm{O}$, Holland D, Waldron J, et al. Reduced testing frequency for glycated hemoglobin, $\mathrm{HbA}_{\mathrm{lc}}$, is associated with deteriorating diabetes control. Diabetes Care 2014; 37: 2731-2737.

21 Marks A, Wilson V, Crisp J. The management of type 1 diabetes in Australian primary schools. Issues Compr Pediatr Nurs 2014; 37: 168-182.

22 Sherr JL, Hermann JM, Campbell F, et al; for the TID Exchange, the DPV Initiative, and the NPDA and the RCP and Child Health registries. Use of insulin pump therapy in children and adolescents with type 1 diabetes and its impact on metabolic control: comparison of results from three large, transatlantic paediatric registries. Diabetologia 2016; 59: 87-91.

23 Johnson SR, Cooper MN, Jones TW, et al. Long-term outcome of insulin pump therapy in children with type 1 diabetes assessed in a large population-based casecontrol study. Diabetologia 2013; 56: 2392-2400.

24 Australian Bureau of Statistics. 4364.0.55.003. Australian Health Survey: updated results, 2011-2012 [website]. June 2013. http://www.abs.gov.au/ausstats/ abs@.nsf/Lookup/4364.0.55.003main+features120112012 (accessed Mar 2016).

25 Islam ST, Abraham A, Donaghue KC, et al. Plateau of adiposity in Australian children diagnosed with type 1 diabetes: a 20-year study. Diabet Med 2014; 31: 686-690.

26 O'Connell MA, Donath S, Cameron FJ. Major increase in type 1 diabetes: no support for the accelerator hypothesis. Diabet Med 2007; 24: 920-923.

27 DuBose S, Hermann J, Tamborlane W, et al. Obesity in youth with type 1 diabetes in Germany, Austria and the United States. J Pediatr 2015; 167: 627-632. 